\title{
Application of probabilistic-based frequency ratio model in groundwater potential mapping using remote sensing data and GIS
}

\begin{abstract}
The main goal of this study is to investigate the application of the probabilistic-based frequency ratio (FR) model in groundwater potential mapping at Langat basin in Malaysia using geographical information system. So far, the approach of probabilistic frequency ratio model has not yet been used to delineate groundwater potential in Malaysia. Moreover, this study includes the analysis of the spatial relationships between groundwater yield and various hydrological conditioning factors such as elevation, slope, curvature, river, lineament, geology, soil, and land use for this region. Eight groundwater-related factors were collected and extracted from topographic data, geological data, satellite imagery, and published maps. About 68 groundwater data with high potential yield values of $\geq 11 \mathrm{~m} 3 / \mathrm{h}$ were randomly selected using statistical software of SPSS. Then, the groundwater data were randomly split into a training dataset $70 \%$ (48 borehole data) for training the model and the remaining $30 \%$ (20 borehole data) was used for validation purpose. Finally, the frequency ratio coefficients of the hydrological factors were used to generate the groundwater potential map. The validation dataset which was not used during the FR modeling process was used to validate the groundwater potential map using the prediction rate method. The validation results showed that the area under the curve for frequency model is $84.78 \%$. As far as the performance of the FR approach is concerned, the results appeared to be quite satisfactory, i.e., the zones determined on the map being zones of relative groundwater potential. This information could be used by government agencies as well as private sectors as a guide for groundwater exploration and assessment in Malaysia.
\end{abstract}

\footnotetext{
Item Article

Type:
}

Keyword: Groundwater potential; Yield; Frequency ratio; Geographic information systems; GIS; Remote sensing; Malaysia 